\title{
Exogenous nitric oxide decreases brain vascular inflammation, leakage and venular resistance during Plasmodium berghei ANKA infection in mice
}

\author{
Graziela M Zanini ${ }^{1,2}$, Pedro Cabrales ${ }^{1,3}$, Wisam Barkho ${ }^{1}$, John A Frangos ${ }^{1}$ and Leonardo JM Carvalho ${ }^{1 *}$
}

\begin{abstract}
Background: Cerebral malaria (CM) is a lethal complication of Plasmodium falciparum infections. In the Plasmodium berghei ANKA (PbA) murine model, CM is associated with marked brain inflammation, increased expression of endothelial cell adhesion molecules and leukocyte and platelet accumulation in brain vessels, causing vascular occlusion and decreased blood flow, damaging the endothelium and leading to blood-brain barrier breakdown, leakage and hemorrhages. Exogenous nitric oxide (NO) administration largely prevents the syndrome. Here we evaluated whether the mechanism of action of $\mathrm{NO}$ in preventing murine $\mathrm{CM}$ is related to its antiinflammatory properties and to protection of the endothelium.

Methods: C57BI/6 mice infected with PbA were treated twice a day with saline or dipropylenetriamineNONOate (DPTA-NO). Endothelial cell adhesion molecule (ICAM-1, VCAM, E- and P-selectin) expression in brain tissue on day 6 of infection was assessed in both groups by western blot. For intravital microscopy studies, DPTA-NO-treated and saline-treated mice with a previously implanted closed cranial window were injected with albumin-FITC, anti-CD45TxR and anti-CD41-FITC antibodies on day 6 of infection for quantification of albumin leakage, leukocyte and platelet adherence in pial vessels.

Results: PbA-infected mice treated with the NO-donor DPTA-NO showed decreased expression of ICAM-1 and P-selectin, but not VCAM-1, in the brain, compared to saline-treated mice. DPTA-NO treatment also decreased the number of adherent leukocytes and platelets in pial vessels, particularly in venules 30-50 $\mu \mathrm{m}$ in diameter, decreased inflammatory vascular resistance and prevented the occurrence of arteriolar and venular albumin leakage observed in saline-treated PbA-infected mice, as assessed by intravital microscopy.

Conclusions: These results indicate that the protective effect of exogenous NO on murine CM is associated with decreased brain vascular expression of inflammatory markers resulting in attenuated endothelial junction damage and facilitating blood flow.
\end{abstract}

\section{Introduction}

Cerebral malaria (CM), a complication of malaria infection by Plasmodium falciparum, is a leading cause of mortality and neurological impairment in endemic areas, with an estimated 1 million deaths every year [1]. In the murine model of $\mathrm{CM}$ by $\mathrm{P}$. berghei ANKA (PbA), the neurological syndrome is associated with several

\footnotetext{
* Correspondence: Icarvalho@ljbi.org

'La Jolla Bioengineering Institute, San Diego, CA, USA

Full list of author information is available at the end of the article
}

indicators of severe vasculopathy and endothelial dysfunction, whose pathogenesis is complex and involves a systemic inflammatory response with activation of CD4+ and CD8+ T cells, macrophages, platelets, release of several pro-inflammatory cytokines such as IFN- $\gamma$, TNF- $\alpha$ and LTA [2-8] as well as depletion of nitric oxide (NO) [9] and increased expression of endothelin-1 and other vasoactive elements $[10,11]$. These events cause the vascular beds in the brain and other organs to upregulate the expression of a number of endothelial cell adhesion

\section{C) Biomed Central}


molecules (eCAMs), including ICAM-1, VCAM-1 and P-selectin [12]. The activated endothelium facilitates the recruitment of different cell types, including monocytes, lymphocytes, platelets and pRBCs, which interact with the eCAMs, roll and adhere, accumulating, and ultimately plugging the brain vessels and causing blood flow disturbances or even complete vascular blockades [13]. Interaction with adherent cells can also result in endothelial cell dysfunction and damage through direct contact or the release of active compounds such as cytokines and perforin, leading to BBB disruption, with leakage of plasma contents into the brain parenchyma which can induce neurotoxicity or contribute to brain edema [14-16]. A damaged vessel may eventually rupture causing the disseminated hemorrhages commonly observed in murine CM $[17,18]$.

Endothelial dysfunction by different mechanisms such as NO depletion can contribute to vascular inflammation. It has been shown that low NO bioavailability or NO inhibition can induce the expression of eCAMs [19-21], platelet activation and adhesion to endothelial cells $[22,23]$ and increase baseline leukocyte rolling and adherence $[24,25]$, and administration of NO donors inhibits endothelial activation [26]. Low NO bioavailability is a major player in vascular inflammation commonly observed in hemolytic syndromes such as sickle cell crisis, in which acellular hemoglobin acts as a strong NO scavenger [27]. Murine CM is associated with low NO bioavailability due largely to NO-scavenging by plasma hemoglobin, and exogenous supplementation of NO to $\mathrm{PbA}$-infected mice largely prevents CM [9]. We have recently shown that this protection is associated with improved cerebral microcirculatory function, as NO supplementation prevented pial vasoconstriction and attenuated the decrease in pial blood flow in $\mathrm{PbA}$ infected mice [18].

In the present study, we show that NO supplementation acts by decreasing eCAM expression in the brain leading to decreased adherence of leukocytes and platelets in pial vessels and preventing vascular leakage in arterioles and venules.

\section{Methods}

\section{Parasite, infection and NO-donor treatment}

Animal handling and care followed the NIH Guide for Care and Use of Laboratory Animals. All protocols were approved by the La Jolla Bioengineering Institutional Animal Care and Use Committee. Eight to 12-week old C57Bl/6 (Jackson Laboratories, ME) were inoculated intraperitoneally (IP) with $1 \times 10^{6}$ Plasmodium berghei ANKA parasites expressing the green fluorescent protein (PbA-GFP, a donation from the Malaria Research and Reference Reagent Resource Center - MR4, Manassas, VA; deposited by CJ Janse and AP Waters; MR4 number: MRA-865). Parasitemia, body weight, rectal temperature and clinical status (using six simple tests adapted from the SHIRPA protocol, as previously described [18], were monitored daily from day 4. Parasitemia was checked by flow cytometry by detecting the number of fluorescent GFP-expressing pRBCs in relation to 10,000 RBCs. CM was defined as the presentation of one or more of the following clinical signs of neurological involvement: ataxia, limb paralysis, poor righting reflex, seizures, roll-over, coma. PbA-infected mice were treated with either saline or dipropylenetriamine NONOate (DPTA-NO, Cayman Chemical, Ann Arbor, MI) $1 \mathrm{mg} /$ mouse, intraperitoneally (IP), twice a day starting on day 0 of infection.

\section{Brain endothelial cell adhesion molecule expression quantification}

On day 6 of infection, saline-treated and DPTA-NOtreated $\mathrm{PbA}$-infected mice, as well as uninfected control mice, were euthanized with $100 \mathrm{mg} / \mathrm{kg}$ of euthasol IP, perfused with saline and the brains collected and frozen at $-80^{\circ} \mathrm{C}$ until processing. Brains were defrosted and homogenized in lysis buffer ( $50 \mathrm{mM}$ Tris pH7.5, 125 $\mathrm{mM} \mathrm{NaCl}, 60 \mathrm{mM}$ octylglucoside, $2 \mathrm{mM}$ sodium vanadate and protease inhibitor cocktail tablets (Complete, Roche), on ice for $30 \mathrm{~min}$ than centrifuged at $14.000 \mathrm{~g}$ for $20 \mathrm{~min}$, the supernatant was diluted and proteins were resolved by sodium dodecyl-sulphate polyacrylamide gel electrophoresis and then transferred onto nitrocellulose membranes (Milipore). Membranes were blocked and probed with antibodies to intercellular cell adhesion molecule-1 (ICAM-1), vascular cell adhesion molecule-1 (VCAM-1), P-selectin or E-selectin (all from BD Biosciences). Detection was performed with anti-IgG secondary antibodies conjugated to peroxidase and reaction was developed with Super Signal West Pico Chemiluminescence Substrate (Thermo Scientific). After development, antibodies were unbound using Restore Western Blot Stripping buffer (Thermo Scientific), reincubated with antibodies to GAPDH (V-18) (Santa Cruz) and reaction was developed by chemiluminescence. The band intensities were determined after scanning the radiographic films and image analysis using Image $(\mathrm{NIH})$ software, and eCAM expression was normalized in relation to GAPDH expression.

\section{Quantification of brain leukocyte and platelet adherence and vascular leakage using intravital microscopy}

The closed cranial window model was used as previously described $[13,28]$. After the implantation of the cranial window, mice rested for 2-4 weeks before starting the experiment. On the day before infection, a panoramic picture of the vascular network under the window was taken and, with the mouse under light 
isoflurane anesthesia, the pial vessels were checked in the intravital microscope and 12 arterioles and venules were randomly selected and marked in the panoramic picture, and diameters measured using an image shear device (Image Shear, Vista Electronics, San Diego, CA). Mice were inoculated with $\mathrm{PbA}$ the next day, followed up and treated with either saline or DPTA-NO as described above. On day 6 of infection, a cocktail containing albumin-FITC (Sigma, St Louis, MO; $50 \mu \mathrm{g}$ ), anti-CD45-TxR antibodies (CalTag, Carlsbad, CA; $4 \mu \mathrm{g}$ ) and anti-CD41-FITC antibodies (CalTag, Carlsbad, CA; $4 \mu \mathrm{g}$ ) was intravenously infused through the tail vein (final volume: $75 \mu \mathrm{L}$ ). The mouse was then lightly anesthetized with isoflurane (4\% for induction, $1-2 \%$ for maintenance) and put on a stereotaxic frame with the head gently held with ear bars. A panoramic picture of the vessels under the window was taken and the mouse was transferred to the intravital microscope stage. Body temperature, measured pre-anesthesia, was maintained with a heating pad. Using water-immersion objectives (20X), blood vessel images were captured (COHU 4815, San Diego, CA) and recorded on video-tape. Diameter measurements of 6-10 pial venules and 2-6 pial arterioles previously selected as described above were performed in each animal. Fifteen minutes after injection of the fluorescent-labeled markers, green fluorescence (518 nm) emitted by albumin-FITC, GFP (PbA pRBC) and anti-CD41-FITC antibodies (platelets) was captured using an ALPHA Vivid: XF100-2 (Omega Optical, Brattleboro, VT), and red fluorescence $(615 \mathrm{~nm})$ emitted by anti-CD45-TxR antibodies was exited and captured with a Vivid Standard: XF42. Adherence was defined as cells remaining static for 30 seconds. For each selected vessel, leukocytes and platelets were quantified in a $100 \mu \mathrm{m}$ long section. The pre-selection of vessels on day 0 to perform the measurements was intended to avoid bias in the quantifications, as different vessels may be heterogeneously affected by leukocyte and platelet adherence. Vascular leakage was measured by quantifying the fluorescence emitted by albumin-FITC (Molecular Probes, Eugene, OR) inside the vessel and in the surrounding tissue, using ALPHA Vivid: XF100-2 (Exciter: XF1073; Dichroic: XF2010; Emitter: XF3084, Omega Filters Brattleboro, VT). The albumin-FITC was injected into the tail vein and 15 min after infusion the fluorescence emission signals were recorded using a photomultiplier (Hamamatsu R928, Tokyo, Japan). Results of leakage are expressed as the ratio of albumin-FITC-derived fluorescence intensity between the tissue and the vessel. Higher ratios correspond to higher leakage. Inflammation effects on vascular resistance were calculated by mathematically using Darcy's law and Hagen-Poiseuille equation relative to without inflammation. These estimations were calculated by each microvessel using the ratio between the microvessel with the volumes occupied by adhered leukocytes relative to without leukocytes and approximating the pressure drop through a non-variable length cylindrical pipe as a function of the diameter to the power of four (area square).

\section{Statistical analysis}

Statistical analyses were performed using analysis of variance (ANOVA) with Dunnett's post-hoc analysis to compare eCAM expression, leukocyte and platelet adherence and vascular leakage in uninfected, salinetreated and DPTA-NO-treated PbA-infected mice. Correlations were established using the Spearmann rank test. All statistics were performed using the Graphpad Prism software (GraphPad Software Inc., La Jolla, CA). A $p$ value $<0.05$ was considered significant.

\section{Results}

DPTA-NO treatment decreases ICAM-1 and P-selectin, but not VCAM-1, expression in the brain of PbA-infected mice In the eCAM expression studies, $79 \%$ of the salinetreated mice $(\mathrm{n}=14)$ showed clinical signs of CM on day 6 of infection, against 29\% of the DPTA-NO-treated mice $(n=14)$. All mice were euthanized regardless of $\mathrm{CM}$ expression and brains were collected. The course of parasitemia was similar in both groups (saline: $10.8 \pm 0.58 \%$; DPTA-NO: $10.2 \pm 0.65 \%$, day 6 of infection). Saline-treated $\mathrm{PbA}$-infected mice showed increased expression of ICAM-1, VCAM-1 and P-selectin, but not E-selectin (Figure 1). ICAM-1 expression was increased nearly 10 -fold, whereas VCAM-1 and Pselectin expression was increased about two-fold in relation to uninfected controls. DPTA-NO treatment caused significant reductions in ICAM-1 and P-selectin expression, but did not significantly modify VCAM-1 expression (Figure 1).

\section{DPTA-NO treatment decreases leukocyte and platelet sequestration in the brain}

Leukocyte/platelet adherence and albumin-FITC leakage were evaluated in pial arterioles and venules ranging from 20 to $50 \mu \mathrm{m}$ in diameter using intravital microscopy. Saline-treated PbA-infected mice showed increased number of sequestered adherent leukocytes and platelets in pial venules on day 6 of infection (Figure 2A,B). Treatment with DPTA-NO significantly reduced the number of both leukocytes and platelets in pial vessels.

\section{DPTA-NO treatment prevents albumin leakage in pial arterioles and venules}

Mice with CM show breakdown of the blood-brain barrier, as generally observed by whole brain leakage of Evans blue dye [29]. Evaluation of albumin leakage in individual vessels by intravital microscopy revealed that 


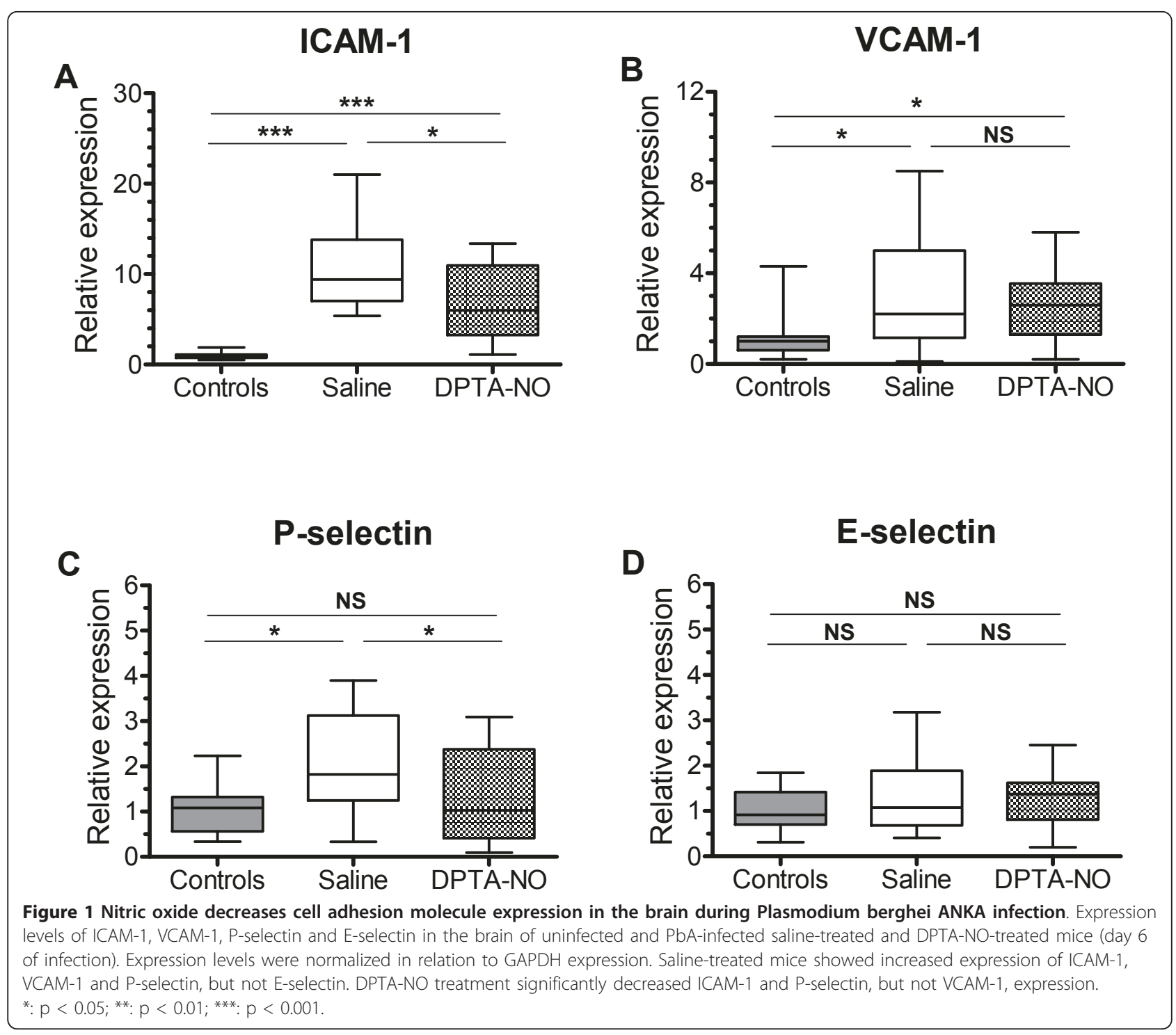

leakage occurred in both arterioles and venules and was prevented by treatment with DPTA-NO (Figure 2C,D).

\section{Adherent leukocytes and platelets, but not leakage, \\ co-localize}

We asked whether vessel size would affect leukocyte/platelet adherence and intensity of leakage in saline-treated $\mathrm{PbA}$-infected mice, and whether venules presenting higher numbers of adherent leukocytes would also present higher platelet adherence and more intense leakage. Leukocyte $\left(r^{2}=0.21\right)$ and platelet $\left(r^{2}=0.15\right)$ adherence, but not albumin leakage $\left(r^{2}=0.03\right)$, were significantly correlated with increasing venular diameters. Vessels with more leukocytes also presented more platelets, this correlation being also present in DPTA-NO-treated mice despite the lower numbers of adherent cells. Platelet adherence $\left(\mathrm{r}^{2}=0.49\right)$, but not leakage $\left(\mathrm{r}^{2}=0.01\right)$, was significantly correlated with leukocyte adherence in venules. No correlation was found between leukocyte or platelet adherence and leakage $\left(r^{2}=0.06\right)$.

Effect of exogenous NO on leukocyte and platelet accumulation differs according to venular diameter DPTA-NO treatment affected the distribution of adherent leukocytes at different microvessel diameters. While in saline-treated animals the number of adherent leukocytes increased with increasing venular diameter, in DPTA-NO-treated mice the distribution of adherent leukocytes was relatively homogeneous in microvessels of different diameters (Figure 3A,B). These results suggest that DPTA-NO largely inhibited leukocyte accumulation in vessels larger, but not smaller, than $30 \mu \mathrm{m}$. 

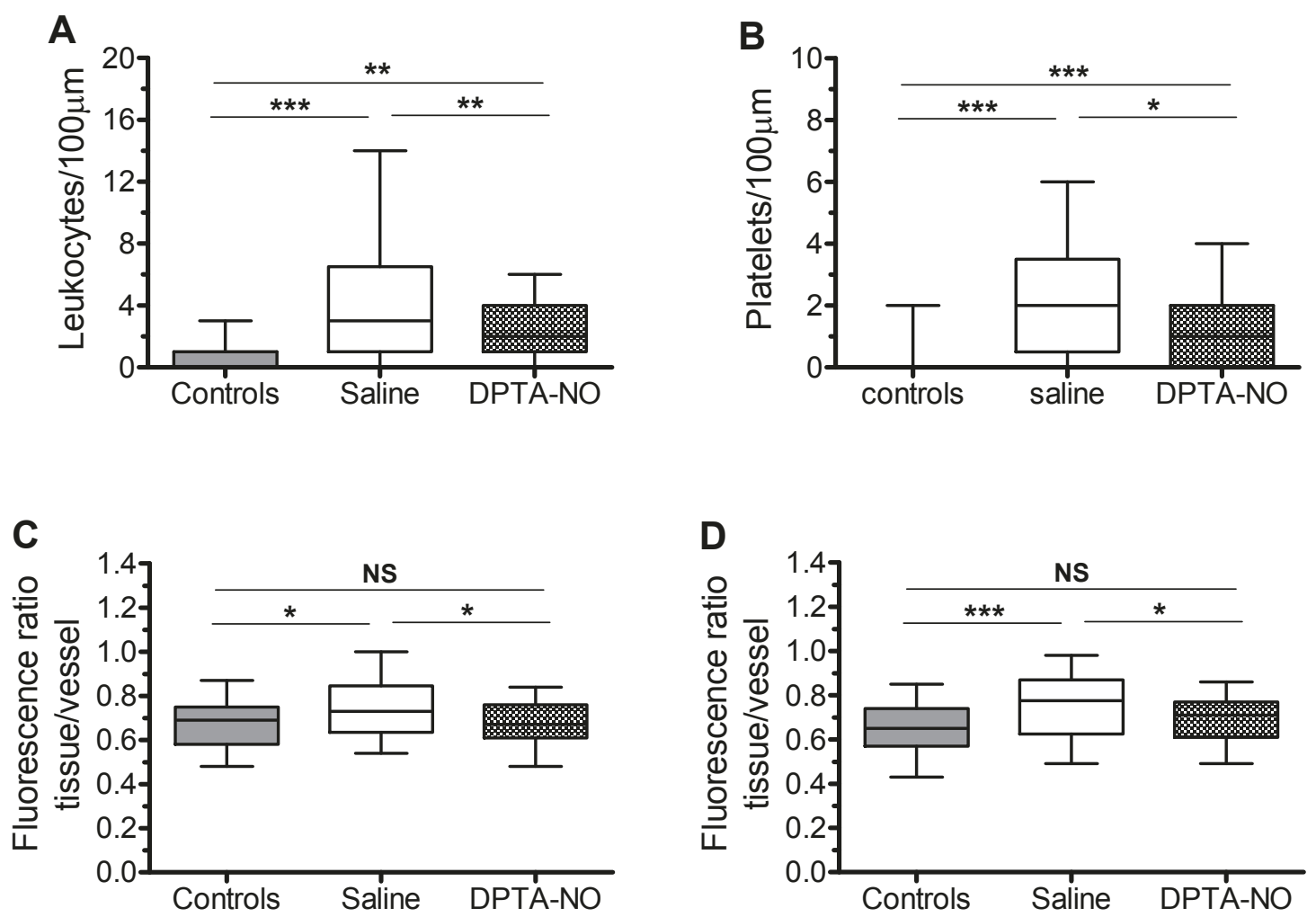

Figure 2 Nitric oxide decreases leukocyte and platelet adherence and vascular leakage during Plasmodium berghei ANKA infection. Mean number of adherent leukocytes (A) and platelets (B) in pial venules, and albumin leakage in arterioles (C) and venules (D) of saline-treated $(n=6)$ and DPTA-NO-treated $(n=6)$ PbA-infected mice on day 6 of infection, and in uninfected control mice $(n=5)$. A total of 6-8 venules and 4-6 arterioles were analyzed per mouse. Saline-treated mice showed increased number of adherent leukocytes and platelets, as well as increased vascular permeability, and DPTA-NO treatment markedly inhibited adherence and leakage. ${ }^{* *}: p<0.01$; **: $p<0.001$; NS: non-significant.

\section{Decrease in leukocyte accumulation by exogenous NO affect vascular resistance}

To analyze the effect of leukocyte accumulation on venular resistance to blood flow, venules were categorized in three groups based on diameter: $20-30 \mu \mathrm{m}, 30$ $40 \mu \mathrm{m}$ and $40-50 \mu \mathrm{m}$. Figure $4 \mathrm{~A}$ shows the mean number of leukocytes and platelets per category. In venules of saline-treated $\mathrm{PbA}$-infected mice, leukocyte accumulation resulted in increased resistance to blood flow, particularly in the range of $20-40 \mu \mathrm{m}$ in diameter (Figure $4 \mathrm{~B})$. Due to larger diameters the degree of leukocyte accumulation in vessels $40-50 \mu \mathrm{m}$-diameter did not substantially affect vascular resistance. DPTA-NO treatment had little effect upon leukocyte accumulation in smaller venules (20-30 $\mu \mathrm{m}$ in diameter) and therefore its effect on decreasing vascular resistance was felt only in vessels in the 30-40 $\mu \mathrm{m}$-diameter range. Because hydrostatic pressure is lower in larger venules, the reduction of vascular resistance in larger venules is expected to increase venous return in DPTA-NO-treated mice.

\section{Discussion}

Murine cerebral malaria is associated with increased expression of eCAMs as well as leukocyte and platelet accumulation in brain vessels leading to microvascular damage and BBB breakdown $[8,30]$. Here we show that exogenous NO supplementation attenuated, although it did not prevent, brain vascular inflammation (eCAM expression, leukocyte and platelet accumulation) and its consequences such as vascular leakage. We have previously shown that exogenous NO supplementation ameliorated pial blood flow, vasoconstriction and the occurrence of brain hemorrhages [18]. Overall, these results indicate that low NO bioavailability has a role in the microvascular dysfunction observed during murine CM [13] and that exogenous NO can help to protect the vasculature, attenuating endothelial damage and dysfunction. The only partial effects of DPTA-NO treatment on inflammatory markers and on brain hemodynamics suggest that NO supplementation provides a subtle beneficial effect on CM pathogenesis, which for a significant 


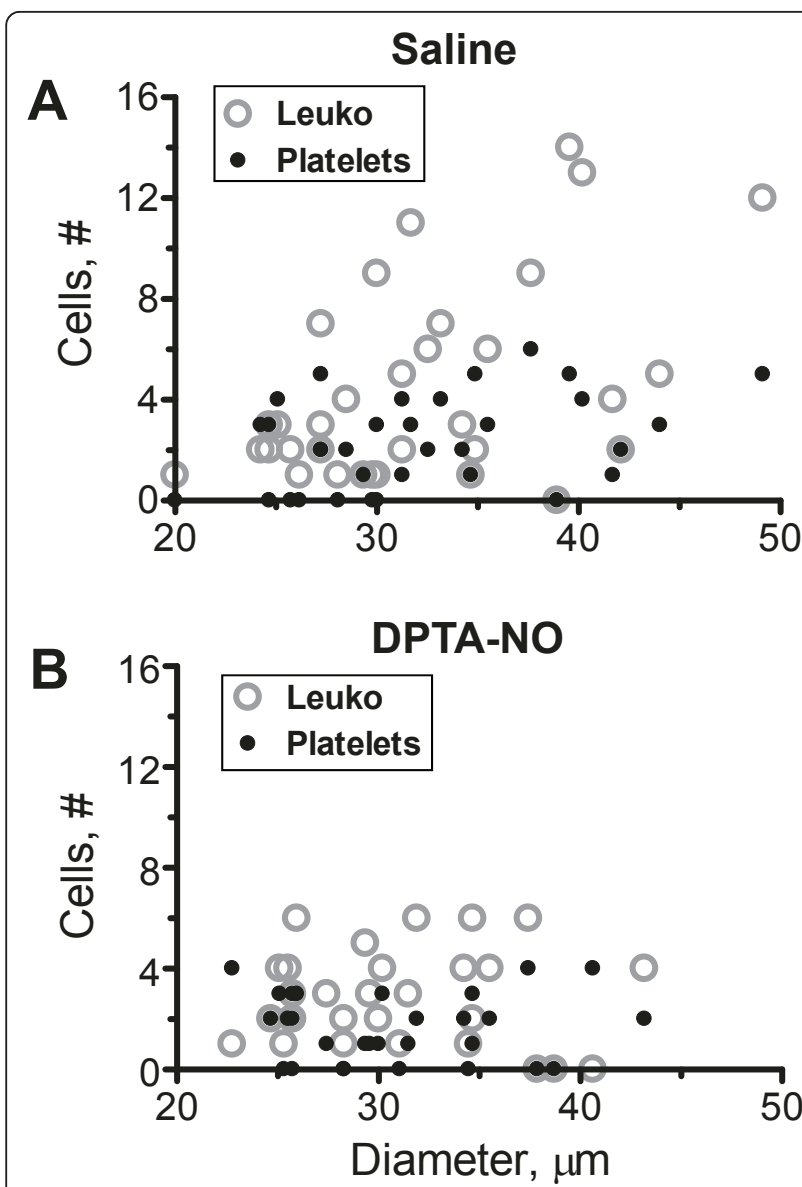

Figure 3 Effect of DPTA-NO treatment on leukocyte and platelet adherence during $\mathrm{PbA}$ infection. (A): Leukocyte and platelet adherence significantly correlate with increasing venular diameters in saline-treated (A) but not in DPTA-NO-treated (B) PbAinfected mice on day 6 of infection.

number of animals can be enough to prevent death by $\mathrm{CM}$, rather than an unmistakable modification of disease history. In addition, the overlap between treated and untreated mice in several of the measured parameters might suggest that NO-mediated mechanisms other than the ones reported here could be responsible for the clinical effect.

Studies of eCAM expression in human and murine CM consistently show an increased expression of ICAM-1, whereas the results for other eCAMs are variable. In cases of fatal human CM, the picture that emerges is of marked increases in ICAM-1, significant but less pronounced increases in VCAM-1 and E-selectin and no changes in P-selectin expression in the brain [31-33]. In murine CM, high expression of ICAM-1 in the brain is consistently observed [12,34,35] and VCAM-1 expression has been shown to be also markedly increased in brain and retinal vessels [12,35]. $\mathrm{P}$-selectin was shown to be increased whereas no change

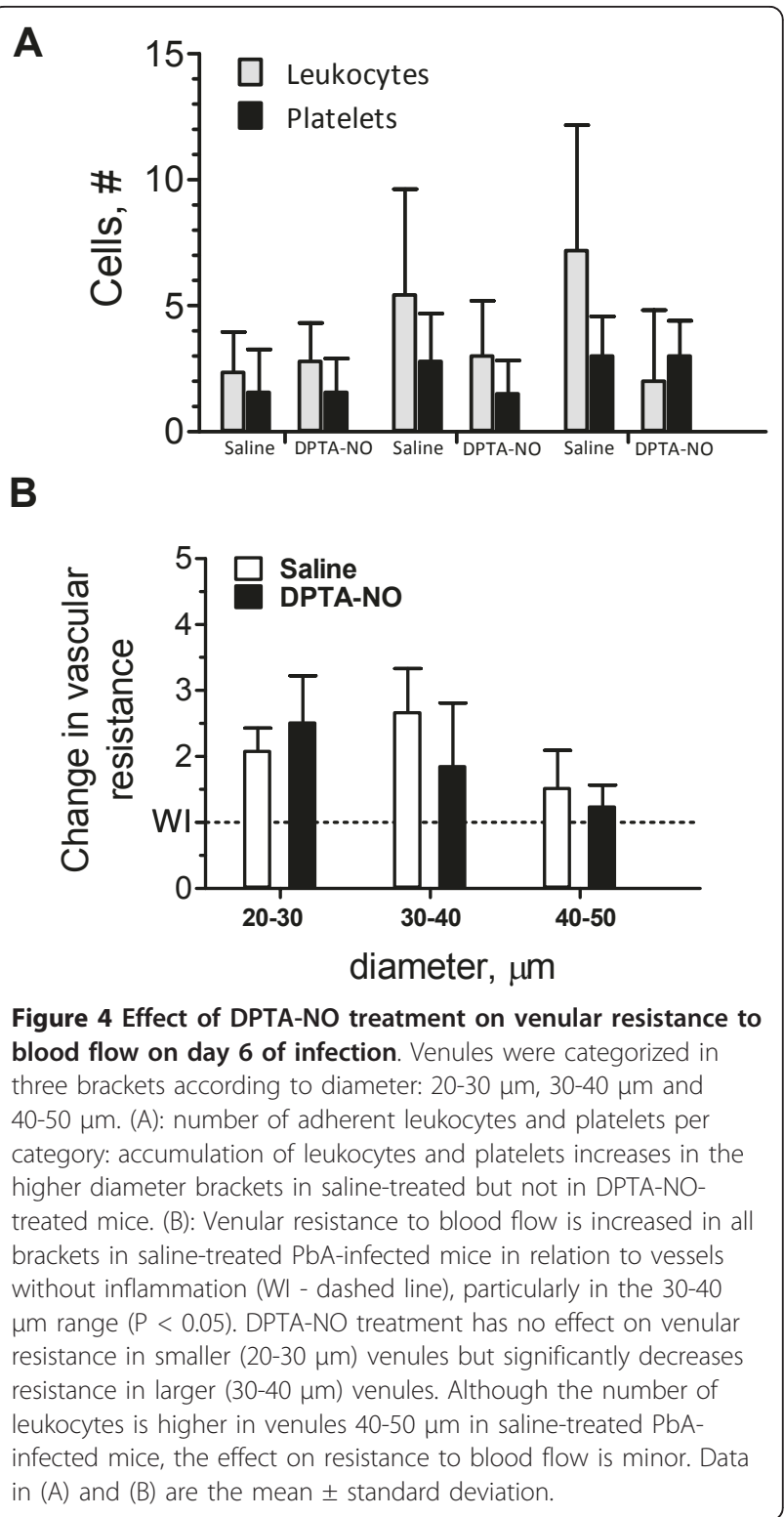

in E-selectin was reported on day 6 of infection $[12,36]$. Similarly, in the present study, we found a marked increase in ICAM-1 expression in the brain on day 6 of infection, VCAM-1 and P-selectin had more modest increases and E-selectin expression was not significantly different in uninfected and saline-treated mice. ICAM-1, indeed, seems to play a relevant role in CM, as not only its expression in brain is consistently markedly increased, but also ICAM-1 gene knockout mice are protected from CM development $[37,38]$. The roles of VCAM-1, E- and P-selectin are less clear. Increased expression of $\mathrm{E}$ - and $\mathrm{P}$-selectin seems to be less intense in the brain as compared to other organs and tissues during $\mathrm{PbA}$ infection and also sepsis [12,39]. Whether the lower magnitude of expression of selectins in the 
brain is relevant for $\mathrm{CM}$ development is debatable. Pselectin gene knockout did not change leukocyte accumulation in the brain during murine $\mathrm{CM}$, and although causing a short delay in mortality it did not prevent it [36].

Low NO bioavailability plays a role in murine CM pathogenesis [9] and it can help to explain the increased expression of eCAMs in brain vessels with the consequent rolling and adherence of leukocytes during $\mathrm{PbA}$ infection. Indeed, impaired NO production by NO synthase (NOS) inhibitors such as L-NAME, or by NOS gene knockout, has been shown to increase eCAM expression in vivo and in vitro [19-21,25]. Increased eCAM expression as well as vascular inflammation and platelet activation are also observed in hemolytic pathologies such as sickle cell crisis, in which cell-free hemoglobin acts as a potent $\mathrm{NO}$ scavenger limiting NO bioavailability [27]. Increased eCAM expression is followed by increased leukocyte rolling and adherence [25], and NO supplementation with $\mathrm{NO}$ donors can inhibit eCAM expression and leukocyte migration $[26,40]$. Here we show that exogenous $\mathrm{NO}$ indeed caused a significant downregulation of ICAM-1 and P-selectin, but not VCAM-1, expression in the brain of PbA-infected mice and, therefore, this may help to explain the protective effect of $\mathrm{NO}$ on murine CM. It is noteworthy, however, that exogenous NO decreased but did not actually prevent ICAM-1 expression, and did not significantly decrease VCAM-1 expression in PbA-infected mice. Accordingly, it decreased but did not prevent leukocyte and platelet accumulation in the brain on day 6 , although it did prevent vascular leakage. While low NO bioavailability is an important component of endothelial dysfunction, it is not the sole cause of vascular inflammation in murine $\mathrm{CM}$, which is the result of a complex cascade of events, including early activation of $\mathrm{T}$ cells [41] and production and release of high levels of several inflammatory cytokines [8]. The partial inhibitory effect of NO supplementation on the inflammatory process during $\mathrm{PbA}$ infection is in agreement with our previous study showing that exogenous NO supplementation with DPTA-NO attenuated but did not inhibit the brain microcirculatory complications in $\mathrm{PbA}$ infection [18].

In saline-treated $\mathrm{PbA}$-infected mice, the venular sites with higher accumulation of leukocytes presented higher platelet counts. Because there were also direct correlations between the number of adherent leukocytes/platelets and venular diameters, this finding indicates that the differential quantitative accumulation was due basically to the larger available area for binding in larger vessels rather than to eventual differential expression of eCAMs in different vascular beds, although the latter was not directly assessed and cannot be ruled out. This is in accordance with previous findings by Sun and colleagues regarding platelet adherence during murine $\mathrm{CM}$ [42]. These results indicate that, during PbA infection, cerebral venules of different sizes in the range analyzed are similarly activated and similarly receptive to leukocyte and platelet adherence. DPTA-NO treatment, however, seems to differentially affect venules according to their size, as it had little effect on leukocyte accumulation in smaller $(20-30 \mu \mathrm{m})$ venules and marked effect in larger (30-50 $\mu \mathrm{m})$ ones. This effect is important not only in the sense that decreased inflammation may help preserve vascular integrity, but also because it decreases leukocyte-induced increases in vascular resistance, therefore increasing venous return and potentially improving blood flow. In our previous study [18], DPTA-NO sustained superior hemodynamics compared to saline, which in part is due to reduced vascular resistance due to geometrical and inflammatory changes. The results of these studies strongly support the view that NO therapy with a stable and long-acting molecule may constitute a useful therapeutic approach to partially decrease receptor-ligands interactions involved in CM cell adhesion and related hemodynamic complications. This may be true as well for mediators such as erythropoietin, which enhances endothelium-dependent vasodilatation mediated by NO in rodent cerebral vessels [43] and prevents vascular inflammation [44] and has also been shown to decrease inflammatory markers and partially protect mice against CM development [45].

Several studies have shown that murine $\mathrm{CM}$ is associated with BBB breakdown with consequent vascular leakage $[29,35]$. Here we studied the vascular leakage at the level of individual pial blood vessels and show that arterioles and venules were similarly affected in $\mathrm{PbA}$ infected mice leading to increased albumin leakage to the brain tissue. Because no correlation was found between leakage and leukocyte/platelet adherence or vessel diameters in venules, and because leakage occurred in arterioles where leukocyte/platelet adherence was minimal, these results indicate that the endothelial dysfunction leading to increased permeability in the brain vessels is not dependent on close contact with inflammatory cells. In our study in no case the studied sites presented evidence of vessel wall rupture, which would lead to massive leakage and hemorrhage. Therefore, although no correlation was found between sites of leakage and of leukocyte/platelet accumulation, we were not able to establish any relation between the latter and more severe vascular damage. Inhibition of NO production can result in increased vascular permeability [46] and therefore the low NO bioavailability during $\mathrm{PbA}$ infection can help to explain increased vascular leakage. Exogenous NO treatment was indeed sufficient to prevent vascular leakage in pial vessels. This is again in accordance with our previous data showing marked 
protection against brain hemorrhages provided by DPTA-NO treatment, despite only partial effect on pial hemodynamics [18].

In summary, exogenous $\mathrm{NO}$ supplementation significantly decreases brain vascular inflammation during $\mathrm{PbA}$ infection by decreasing the expression of eCAMs and consequently decreasing recruitment of leukocytes and platelets, which eventually results in decreased vascular dysfunction and damage.

\section{Acknowledgements}

This work was supported with funds from the United States National Institutes of Health grants R01-HL87290 and R01-AI082610 (L.J.M.C.). G.M.Z. was recipient of a CNPq (Brazil) post-doctoral fellowship. We thank John Nolan (LJBI) for granting access to the flow cytometry facilities, and JiunnChern Yeh and Benoit Melchior (LJBI) for initial assistance in the western blot experiments.

\section{Author details}

${ }^{1}$ La Jolla Bioengineering Institute, San Diego, CA, USA. ${ }^{2}$ Parasitology Service, Instituto de Pesquisas Clinicas Evandro Chagas, Fiocruz, Rio de Janeiro, Brazil. ${ }^{3}$ Department of Bioengineering, University of California, San Diego, CA, USA.

\section{Authors' contributions}

GMZ infected and treated the mice and performed the eCAM expression studies, analyzed and interpreted data and wrote the manuscript; PC performed the intravital microscopy studies, analyzed and interpreted data and performed statistical analysis; WB participated in the intravital microscopy experiments; JAF analyzed and interpreted data; LJMC designed research, analyzed and interpreted data and wrote the manuscript. All authors have read and approved the final version of this manuscript.

\section{Competing interests}

The authors declare that they have no competing interests.

Received: 4 April 2011 Accepted: 7 June 2011 Published: 7 June 2011

\section{References}

1. Rowe AK, Rowe SY, Snow RW, Korenromp EL, Schellenberg JR, Stein C, Nahlen BL, Bryce J, Black RE, Steketee RW: The burden of malaria mortality among African children in the year 2000. Int J Epidemiol 2006, 35:691-704.

2. Grau GE, Piguet PF, Engers HD, Louis JA, Vassalli P, Lambert PH: L3T4+ T lymphocytes play a major role in the pathogenesis of murine cerebral malaria. J Immunol 1986, 137:2348-2354.

3. Grau GE, Fajardo LF, Piguet PF, Allet B, Lambert PH, Vassalli P: Tumor necrosis factor (cachectin) as an essential mediator in murine cerebral malaria. Science 1987, 237:1210-1212.

4. Grau GE, Heremans H, Piguet PF, Pointaire P, Lambert PH, Billiau A, Vassalli $P$ : Monoclonal antibody against interferon gamma can prevent experimental cerebral malaria and its associated overproduction of tumor necrosis factor. Proc Natl Acad Sci USA 1989, 86:5572-5574.

5. Engwerda CR, Mynott TL, Sawhney S, De Souza JB, Bickle QD, Kaye PM: Locally up-regulated lymphotoxin alpha, not systemic tumor necrosis factor alpha, is the principle mediator of murine cerebral malaria. J Exp Med 2002, 195:1371-1377.

6. Belnoue E, Kayibanda M, Vigario AM, Deschemin JC, van Rooijen N, Viguier M, Snounou G, Rénia L: On the pathogenic role of brainsequestered alphabeta CD8+ T cells in experimental cerebral malaria. J Immunol 2002, 169:6369-6375.

7. Yañez DM, Manning DD, Cooley AJ, Weidanz WP, van der Heyde HC: Participation of lymphocyte subpopulations in the pathogenesis of experimental murine cerebral malaria. J Immunol 1996, 157:1620-1624.

8. van der Heyde HC, Nolan J, Combes V, Gramaglia I, Grau GE: A unified hypothesis for the genesis of cerebral malaria: sequestration, inflammation and hemostasis leading to microcirculatory dysfunction. Trends Parasitol 2006, 22:503-508.
9. Gramaglia I, Sobolewski P, Meays D, Contreras R, Nolan JP, Frangos JA, Intaglietta M, van der Heyde HC: Low nitric oxide bioavailability contributes to the genesis of experimental cerebral malaria. Nat Med 2006, 12:1417-1422.

10. Machado FS, Desruisseaux MS, Nagajyothi, Kennan RP, Hetherington HP Wittner M, Weiss LM, Lee SC, Scherer PE, Tsuji M, Tanowitz HB: Endothelin in a murine model of cerebral malaria. Exp Biol Med 2006, 231:1176-1181.

11. Desruisseaux MS, Machado FS, Weiss LM, Tanowitz HB, Golightly LM: Cerebral malaria: a vasculopathy. Am J Pathol 2010, 176:1075-1078.

12. Bauer PR, Van Der Heyde HC, Sun G, Specian RD, Granger DN: Regulation of endothelial cell adhesion molecule expression in an experimental model of cerebral malaria. Microcirculation 2002, 9:463-470.

13. Cabrales P, Zanini GM, Meays D, Frangos JA, Carvalho LJM: Murine Cerebral malaria is associated with a vasospasm-like microcirculatory dysfunction and survival upon rescue treatment is markedly increased by nimodipine. Am J Pathol 2010, 176:1306-1315.

14. Nitcheu J, Bonduelle O, Combadiere C, Tefit M, Seilhean D, Mazier D, Combadiere B: Perforin-dependent brain-infiltrating cytotoxic CD8+ T lymphocytes mediate experimental cerebral malaria pathogenesis. $\mathrm{J}$ Immunol 2003, 170:2221-2228.

15. Potter S, Chan-Ling T, Ball HJ, Mansour H, Mitchell A, Maluish L, Hunt NH: Perforin mediated apoptosis of cerebral microvascular endothelial cells during experimental cerebral malaria. Int J Parasitol 2006, 36:485-496.

16. Lackner P, Burger C, Pfaller K, Heussler V, Helbok R, Morandell M, Broessner G, Tannich E, Schmutzhard E, Beer R: Apoptosis in experimental cerebral malaria: spatial profile of cleaved caspase-3 and ultrastructural alterations in different disease stages. Neuropathol Appl Neurobiol 2007, 33:560-571.

17. Carvalho LJM, Lenzi HL, Pelajo-Machado M, Oliveira DN, Daniel-Ribeiro CT, Ferreira-da-Cruz MF: Plasmodium berghei: cerebral malaria in CBA mice is not clearly related to plasma TNF levels or intensity of histopathological changes. Exp Parasitol 2000, 95:1-7.

18. Cabrales P, Zanini GM, Meays D, Frangos JA, Carvalho LJM: Nitric oxide protection against murine cerebral malaria is associated with improved cerebral microcirculatory physiology. J Infect Dis 2011, 203:1454-1463.

19. Davenpeck KL, Gauthier TW, Lefer AM: Inhibition of endothelial-derived nitric oxide promotes $\mathrm{P}$-selectin expression and actions in the rat microcirculation. Gastroenterology 1994, 107:1050-1058.

20. Luvarà G, Pueyo ME, Philippe M, Mandet C, Savoie F, Henrion D, Michel JB: Chronic blockade of NO synthase activity induces a proinflammatory phenotype in the arterial wall: prevention by angiotensin II antagonism. Arterioscler Thromb Vasc Biol 1998, 18:1408-1416.

21. Scalia R, Appel JZ, Lefer AM: Leukocyte-endothelium interaction during the early stages of hypercholesterolemia in the rabbit: role of P-selectin, ICAM-1, and VCAM-1. Arterioscler Thromb Vasc Biol 1998, 18:1093-1100.

22. Schäfer A, Bauersachs J: Endothelial dysfunction, impaired endogenous platelet inhibition and platelet activation in diabetes and atherosclerosis. Curr Vasc Pharmacol 2008, 6:52-60.

23. Hiratsuka M, Katayama T, Uematsu K, Kiyomura M, Ito M: In vivo visualization of nitric oxide and interactions among platelets, leukocytes, and endothelium following hemorrhagic shock and reperfusion. Inflamm Res 2009, 58:463-471.

24. Kubes P, Suzuki M, Granger DN: Nitric oxide: an endogenous modulator of leukocyte adhesion. Proc Natl Acad Sci USA 1991, 88:4651-4655.

25. Lefer DJ, Jones SP, Girod WG, Baines A, Grisham MB, Cockrell AS, Huang PL, Scalia R: Leukocyte-endothelial cell interactions in nitric oxide synthasedeficient mice. Am J Physiol 1999, 276:H1943-1950.

26. Zampolli A, Basta G, Lazzerini G, Feelisch M, De Caterina R: Inhibition of endothelial cell activation by nitric oxide donors. J Pharmacol Exp Ther 2000, 295:818-823.

27. Conran N, Franco-Penteado CF, Costa FF: Newer aspects of the pathophysiology of sickle cell disease vaso-occlusion. Hemoglobin 2009, 33:1-16.

28. Cabrales P, Carvalho LJM: Intravital microscopy of the mouse brain microcirculation using a closed cranial window. J Vis Exp 2011, 45:2184.

29. Thumwood CM, Hunt NH, Clark IA, Cowden WB: Breakdown of the bloodbrain barrier in murine cerebral malaria. Parasitology 1988, 96:579-589.

30. de Souza JB, Hafalla JC, Riley EM, Couper KN: Cerebral malaria: why experimental murine models are required to understand the pathogenesis of disease. Parasitology 2010, 137:755-772. 
31. Silamut K, Phu NH, Whitty C, Turner GD, Louwrier K, Mai NT, Simpson JA, Hien TT, White NJ: A quantitative analysis of the microvascular sequestration of malaria parasites in the human brain. Am J Pathol 1999, 155:395-410.

32. Turner GD, Morrison H, Jones M, Davis TM, Looareesuwan S, Buley ID, Gatter KC, Newbold Cl, Pukritayakamee S, Nagachinta B, White NJ, Berendt AR: An immunohistochemical study of the pathology of fatal malaria. Evidence for widespread endothelial activation and a potential role for intercellular adhesion molecule-1 in cerebral sequestration. Am J Pathol 1994, 145:1057-1069.

33. Armah H, Wired EK, Dodoo AK, Adjei AA, Tettey Y, Gyasi R: Cytokines and adhesion molecules expression in the brain in human cerebral malaria. Int J Environ Res Public Health 2005, 2:123-131.

34. Grau GE, Pointaire P, Piguet PF, Vesin C, Rosen H, Stamenkovic I, Takei F, Vassalli P: Late administration of monoclonal antibody to leukocyte function-antigen 1 abrogates incipient murine cerebral malaria. Eur $J$ Immunol 1991, 21:2265-2267.

35. Ma N, Hunt NH, Madigan MC, Chan-Ling T: Correlation between enhanced vascular permeability, up-regulation of cellular adhesion molecules and monocyte adhesion to the endothelium in the retina during the development of fatal murine cerebral malaria. Am J Pathol 1996, 149:1745-1762

36. Chang WL, Li J, Sun G, Chen HL, Specian RD, Berney SM, Granger DN, van der Heyde HC: P-selectin contributes to severe experimental malaria but is not required for leukocyte adhesion to brain microvasculature. Infect Immun 2003, 71:1911-1918.

37. Favre N, Da Laperousaz C, Ryffel B, Weiss NA, Imhof BA, Rudin W, Lucas R, Piguet PF: Role of ICAM-1 (CD54) in the development of murine cerebral malaria. Microbes Infect 1999, 1:961-968.

38. Li J, Chang WL, Sun G, Chen HL, Specian RD, Berney SM, Kimpel D, Granger DN, van der Heyde HC: Intercellular adhesion molecule 1 is important for the development of severe experimental malaria but is not required for leukocyte adhesion in the brain. $J$ Investig Med 2003, 51:128-140.

39. Vachharajani V, Vital S, Russell J, Scott LK, Granger DN: Glucocorticoids inhibit the cerebral microvascular dysfunction associated with sepsis in obese mice. Microcirculation 2006, 13:477-487.

40. De Caterina R, Libby P, Peng HB, Thannickal VJ, Rajavashisth TB, Gimbrone MA Jr, Shin WS, Liao JK: Nitric oxide decreases cytokineinduced endothelial activation. Nitric oxide selectively reduces endothelial expression of adhesion molecules and proinflammatory cytokines. J Clin Invest 1995, 96:60-68.

41. Carvalho LJ, Ferreira-da-Cruz MF, Daniel-Ribeiro CT, Pelajo-Machado M, Lenzi HL: Germinal center architecture disturbance during Plasmodium berghei ANKA infection in CBA mice. Malar J 2007, 6:59.

42. Sun G, Chang WL, Li J, Berney SM, Kimpel D, van der Heyde HC: Inhibition of platelet adherence to brain microvasculature protects against severe Plasmodium berghei malaria. Infect Immun 2003, 71:6553-6561.

43. Santhanam AV, Smith LA, Nath KA, Katusic ZS: In vivo stimulatory effect of erythropoietin on endothelial nitric oxide synthase in cerebral arteries. Am J Physiol Heart Circ Physiol 2006, 291:H781-786.

44. Toba H, Nakashima K, Oshima Y, Kojima Y, Tojo C, Nakano A, Wang J, Kobara M, Nakata T: Erythropoietin prevents vascular inflammation and oxidative stress in subtotal nephrectomized rat aorta beyond haematopoiesis. Clin Exp Pharmacol Physiol 2010, 37:1139-1146.

45. Wiese L, Hempel C, Penkowa M, Kirkby N, Kurtzhals JA: Recombinant human erythropoietin increases survival and reduces neuronal apoptosis in a murine model of cerebral malaria. Malar J 2008, 7:3.

46. Kurose I, Kubes P, Wolf R, Anderson DC, Paulson J, Miyasaka M, Granger DN: Inhibition of nitric oxide production. Mechanisms of vascular albumin leakage. Circ Res 1993, 73:164-171.

doi:10.1186/1742-2094-8-66

Cite this article as: Zanini et al:: Exogenous nitric oxide decreases brain vascular inflammation, leakage and venular resistance during Plasmodium berghei ANKA infection in mice. Journal of Neuroinflammation 2011 8:66.

\section{Submit your next manuscript to BioMed Central and take full advantage of:}

- Convenient online submission

- Thorough peer review

- No space constraints or color figure charges

- Immediate publication on acceptance

- Inclusion in PubMed, CAS, Scopus and Google Scholar

- Research which is freely available for redistribution

Submit your manuscript at www.biomedcentral.com/submit
Ciomed Central 